\title{
USO E MANUSEIO DE AGROTÓXICOS NA PRODUÇÃO DE ALIMENTOS DA AGRICULTURA FAMILIAR E SUA RELAÇÃO COM A SAÚDE E O MEIO AMBIENTE
}

\author{
M. A. BUSATO*, B. A. AREZI, M. A. SOUZA, C. R. P. A. TEO, J. A. LUTINSKI, L. FERRAZ \\ Universidade Comunitária da Região de Chapecó - UNOCHAPECÓ- Chapecó, SC \\ assunta@unochapeco.edu.br ${ }^{*}$
}

Artigo submetido em 24/08/2016 e aceito em 22/02/2019

DOI: $10.15628 /$ holos. 2019.5006

\section{RESUMO}

O objetivo deste estudo foi conhecer as práticas de uso e manuseio de agrotóxicos na produção de alimentos na agricultura familiar e sua relação com a saúde e o ambiente. Estudo exploratório descritivo com 38 agricultores familiares da região oeste do estado de Santa Catarina (SC). Os participantes foram os pais de estudantes matriculados no ensino médio e técnico da Escola Familiar Rural Santo Agostinho no município de Quilombo (SC). A análise dos dados foi por meio da aplicação de estatística descritiva. Todos os respondentes informaram que produzem alimentos para o autoconsumo e para comercialização. Relataram que trabalhar com agrotóxicos é perigoso, porém, $85 \%$ deles os utilizam na produção. Ao todo $79 \%$ afirmaram usar Equipamento de Proteção Individual parcialmente. A aplicação é realizada de forma manual e mecanizada, com duração de duas a quatro horas por dia, de três a oito vezes por mês, pelo menos há mais de dez anos. Os agricultores relataram que enviam as embalagens de volta para os pontos de venda ou para os centros de recolhimento. Também reutilizam, incineram ou descartam ao ar livre. Os participantes apontaram sintomas como dor de cabeça, tosse, náuseas, câimbra, irritação nos olhos, boca e garganta após aplicação dos agrotóxicos. Foi observada uma preocupação com a proteção da saúde e com o meio ambiente quanto à aplicação de agrotóxicos. No entanto, verificou-se dificuldade na utilização de Equipamento de Proteção Individual, destino adequado das embalagens e carência de orientações e assistência sobre o uso desses produtos, o que poderia contribuir para o cultivo de alimentos mais saudáveis e um maior cuidado com a saúde e o meio ambiente.

PALAVRAS-CHAVE: Sustentabilidade, Agrotóxicos, Saúde, Ambiente

\section{USING AND HANDLING OF PESTICIDES IN FOOD PRODUCTION OF FAMILY FARMING AND ITS RELATION TO HEALTH AND ENVIRONMENT}

\section{ABSTRACT}

The objective of this study was Knowing the family farming practices of using and handling pesticides in food production and its relation to health and environment. A descriptive exploratory study was conducted with 38 family farmers in the western region of Santa Catarina (SC) state. Participants were the parents of students enrolled in Rural Family School Santo Agostinho in Quilombo city (SC). Data analysis was carried out through descriptive statistics. All respondents reported they produce food for self-consumption and for marketing. They reported that working with pesticides is dangerous; however, $85 \%$ of them use pesticides in production while $79 \%$ claim to use Personal Protective Equipment. Men and women carry out the application, in manual and mechanized way, lasting from two up to four hours a day, three to eight times a month, at least for over ten years.
The farmers reported that they send the packaging back to sale points or to collection centers, as well as they also informed its reusing, incinerating or disposing outdoors. The participants pointed out symptoms such as headache, cough, nausea, cramps and irritation of the eyes, mouth and throat after the application of pesticides. We observed a concern about the protection of health and the environment regarding the application of pesticides, however, there was difficulties about the use of Personal Protective Equipment, proper disposal of packaging and lack of guidance and assistance on the use of these products, which could contribute to the cultivation of healthier foods.

KEYWORDS: Sustainability, Pesticides, Health, Environment 


\section{INTRODUÇÃO}

O uso de agrotóxico na agricultura familiar começou a se difundir principalmente nos últimos trinta anos, e o Brasil, esta entre os maiores consumidores de agrotóxicos no mundo. Em 2008, o Brasil ultrapassou os Estados Unidos e assumiu o posto de maior mercado mundial de agrotóxicos (Abrasco, 2012; Casal et al., 2014).

Para a Associação Brasileira de Saúde Coletiva, o processo produtivo agrícola brasileiro está cada vez mais dependente dos agrotóxicos. Os resíduos tóxicos estão presentes em muitos produtos alimentícios, principalmente nos alimentos processados que têm como ingredientes os derivados de trigo, milho e soja, provocando o aumento da insegurança alimentar para o mercado consumidor (Abrasco, 2012; Consea, 2012). Entre os mais contaminados, estão os alimentos in natura, registrando-se que os vegetais e frutas disponíveis no mercado apresentam um aspecto agradável, embora contenha em sua película externa grande quantidade de agrotóxicos utilizados para sua produção (Para, 2014; Consea, 2012). O uso de defensivos agrícolas em grande escala afeta a saúde da população e o meio ambiente, gerando contaminação do solo, do ar, da água, das nascentes e dos aquíferos (EMBRAPA, 2011).

Os agrotóxicos usados na agricultura (inseticidas, herbicidas, fungicidas) e no ambiente doméstico (raticidas, moluscocidas, fumigantes) estão associados a efeitos graves à saúde, causando intoxicações agudas e crônicas (Abrasco, 2012). Os sintomas relacionados às intoxicações agudas ocorrem de forma rápida, logo após a exposição, ocasionando dores de cabeça, sangramento nasal, fraqueza, tontura, espasmos musculares, náuseas e vômitos. Já os sintomas crônicos surgem após meses, anos ou décadas de exposição e podem estar relacionadas com o desenvolvimento de várias doenças, incluindo efeitos neurotóxicos, lesões hepáticas e renais, dentre outras (Londres, 2011; Abrasco, 2012). Os impactos nos processos produtivos da agricultura familiar de maior relevância para a saúde humana e ambiental são as poluições, contaminações ambientais e as intoxicações agudas e crônicas relacionadas à aplicação de agrotóxicos, visto que nem sempre as práticas produtivas são coerentes com as preocupações do impacto ambiental ou expressam visão de sustentabilidade (Abrasco, 2012).

Grande parte dos agrotóxicos aplicados na agricultura tende a escoar principalmente nas águas superficiais e subterrâneas, além de ficarem dispersos na atmosfera. São vários os fatores de degradação ambiental que ocorre com a dispersão de agrotóxicos no ambiente, um dos principais problemas apresentado é a mineralização completa da molécula ou geradores de metabólitos e produtos de degradação (Embrapa, 2011).

$\mathrm{Na}$ região oeste de Santa Catarina, a agricultura familiar tem se apresentado, historicamente, como uma forma de organização dos meios de produção e um modo de vida fundamental para a reprodução social dos agricultores (Badalotti, Renk \& Filippin, 2007). A agricultura familiar da região produz uma diversidade de alimentos, tais como grãos, oleaginosas, frutas e hortaliças, além de tabaco. O cultivo é baseado no espaço disponível para cada cultura, sendo que a produção atende às necessidades das famílias e do mercado consumidor (Minetto, 2013). A agricultura familiar catarinense é das mais dinâmicas e diversificadas do país, representando a base produtiva do setor agropecuário do estado. Este cenário evidencia a 
relevância que assumem as questões relativas ao uso e manuseio de agrotóxicos nesta região, reforçando-se que inadequações neste campo podem, a médio e longo prazo, gerar níveis de contaminação do ambiente de difícil reversão, com consequente implicação na saúde humana (Epagri, 2014). Diante destas ponderações, este estudo teve como objetivo conhecer as práticas de uso e manuseio de agrotóxicos na produção de alimentos na agricultura familiar e sua relação com a saúde e o ambiente.

\section{METODOLOGIA}

Este estudo é do tipo exploratório de caráter descritivo. A pesquisa foi realizada com os agricultores familiares cujos filhos estudam no ensino médio e técnico da Escola Familiar Rural Santo Agostinho do município de Quilombo, SC. Os agricultores participantes deste estudo residem nos municípios de Quilombo, Jardinópolis, Santiago do Sul e União do Oeste. Foram distribuídos 74 questionários, destes foram utilizados para a pesquisa $38(51,3 \%)$, sendo excluídos os instrumentos das famílias que residem na zona urbana $(n=14 ; 18,9 \%)$, as que devolveram com dados incompletos ( $n=4 ; 5,4 \%)$ e as que não assinaram ( $n=18 ; 24,3 \%)$ o Termo de Consentimento Livre e Esclarecido (TCLE). $O$ instrumento da pesquisa contou com perguntas abertas e fechadas cuja elaboração foi adaptada de Netto (2007) e Cizenando (2012). Os principais assuntos abordados na pesquisa foram os grupos alimentares produzidos pelos agricultores familiares, forma e aplicação dos agrotóxicos, uso de equipamento de proteção individual, tempo e período de aplicação, condições climáticas da aplicação, tipos e forma de aquisição de agrotóxicos, descarte das embalagens, período de carência para o consumo e comercialização dos alimentos, ingestão de alimentos durante a aplicação e sintomas após a aplicação dos agrotóxicos.

$\mathrm{Na}$ escola, os estudantes receberam orientações sobre o questionário a ser respondido pelos pais e sobre o Termo de Consentimento Livre e Esclarecido, instrumentos que deveriam ser preenchidos e devolvidos pelos que concordassem em participar do estudo. Os dados oriundos do instrumento de pesquisa foram apresentados de forma descritiva e agrupados pela frequência e percentual.

De acordo com a Resolução n. 466/2012, do Conselho Nacional de Saúde, foram respeitados todos os preceitos éticos e a pesquisa foi aprovada pelo Comitê de Ética em Pesquisa com Seres Humanos da Universidade Comunitária da Região de Chapecó (Unochapecó), sob o parecer n. 1.051.504/2015.

\section{RESULTADOS}

Das famílias que fizeram parte deste estudo ( $N=38)$, residem em Quilombo ( $n=33 ; 86,8 \%)$, União do Oeste $(n=2 ; 5,2 \%)$, Santiago do Sul $(n=2 ; 5,2 \%)$ e Jardinópolis $(n=1 ; 2,6 \%)$. Os respondentes dos questionários, pais e as mães dos estudantes, têm escolaridade em nível de ensino médio incompleto ( $n=34 ; 89,5 \%)$ e ensino superior completo ( $n=4 ; 10,5 \%)$. Todas as famílias são proprietárias dos estabelecimentos rurais, cujas áreas de terra variam de cinco a 70 hectares produzindo alimentos para autoconsumo e comercialização. Os principais alimentos cultivados para o consumo da família sem o uso de agrotóxicos são as frutas (laranja, bergamota, mamão e 
banana) hortaliças (alface, temperos e especiarias naturais) e legumes (pepino, cenoura, rabanete e beterraba). Por outro lado, os demais alimentos, como arroz, feijão, milho e soja, são produzidos com agrotóxicos.

Todos os produtores rurais relataram que trabalhar com agrotóxicos é perigoso, porém, esta prática é adotada pela maioria $(n=32 ; 84,2 \%)$ dos agricultores. A prática do uso dos Equipamentos de Proteção Individual (EPI) é seguida parcialmente por parte deles ( $n=30 ; 78,9 \%$ ) e todos afirmam que a utilização é necessária.

A forma de aplicação dos agrotóxicos ocorre com pulverizadores costais ( $n=14 ; 36,8 \%$ ) e trator ( $n=8 ; 21,1 \%)$. Cada aplicação tem uma duração média de duas a quatro horas por dia e se repete por três a oito vezes ao mês, prática que os respondentes referem ser realizada, pelo menos, há mais de dez anos nas propriedades. Todos os agricultores relatam que aplicam os produtos em condições climáticas favoráveis, seguindo as recomendações da Empresa Brasileira de Pesquisa Agropecuária (EMBRAPA, 2005). Sobre o período de carência para o uso de agrotóxicos, a maioria dos agricultores $(n=33 ; 86,8 \%)$ refere que respeita este período, que é específico para cada cultura, antes de proceder à colheita.

Os agrotóxicos mais utilizados pelos agricultores participantes são inseticidas $(n=28$; $73,7 \%)$, herbicidas ( $n=24 ; 63,2 \%)$, fungicidas ( $n=18 ; 47,4 \%)$, raticidas ( $n=15 ; 39,5 \%)$, acaricidas, moluscocidas e fumigantes $(n=11 ; 28,9 \%)$, os quais são adquiridos em lojas agropecuárias. Contudo, $23,7 \%$ ( $n=9)$ referem não receber orientação no momento da compra, e os que relatam recebê-las, indicam que são técnicos $(n=20 ; 52,6 \%)$ ou vendedores $(n=8 ; 21,1 \%)$ que costumam orientá-los. Os que não recebem orientações técnicas ( $n=10 ; 26,3 \%)$, as buscam com amigos e vizinhos.

Após a compra e pulverização, os agricultores descartam as embalagens para as centrais de recolhimento ( $n=24 ; 63,1 \%)$, as retornam para os pontos de venda ( $n=6 ; 15,79 \%$ ), incineram e descartam ao ar livre ou no entorno da propriedade $(n=3 ; 7,8 \%)$ ou, ainda, as utilizam para armazenamento de água e outros produtos ( $n=5 ; 13,1 \%)$.

Durante a aplicação dos agrotóxicos alguns agricultores familiares fumam $(n=1 ; 2,6 \%)$ e bebem água $(n=3 ; 7,9 \%)$. Com relação aos sintomas após a aplicação dos agrotóxicos, os agricultores relataram sentir dor de cabeça $(n=12 ; 31,8 \%)$, tosse $(n=5 ; 13,2 \%)$, irritação nos olhos/náuseas ( $n=3 ; 7,9 \%)$, irritação na boca/garganta $(n=2 ; 5,3 \%)$ e câimbras/fraqueza ( $n=3$; 7,9\%). Quanto aos casos de intoxicações crônicas, $84 \%$ dos agricultores relataram não terem ocorrido casos na família.

\section{DISCUSSÃO}

Os alimentos produzidos pelos agricultores familiares participantes deste estudo com agrotóxicos são cereais e leguminosas. Já os alimentos produzidos principalmente para o autoconsumo, como frutas, verduras e legumes, são cultivados sem uso de agrotóxicos.

A agricultura familiar é responsável pela produção de diferentes gêneros alimentícios, que atendem às necessidades dos consumidores e da própria família. As práticas para o autoconsumo e a comercialização se mantêm, principalmente, no âmbito da agricultura familiar e vêm 
representando estratégias importantes de geração de renda e de segurança alimentar e nutricional para os agricultores e também para os consumidores (Badalotti, Renk \& Filippin, 2007).

É nessa perspectiva da segurança alimentar e de minimização dos efeitos dos agrotóxicos sobre a saúde que os agricultores respeitam o período de carência referente à aplicação de agrotóxicos, compreendido como o número de dias entre a última aplicação e a colheita. Este período é estabelecido de acordo com as informações do fabricante disponíveis nos rótulos das embalagens de cada produto, recomendado e certificado pela Agência Nacional de Vigilância Sanitária (Embrapa, 2010). Tal como foi relatado pelos agricultores familiares, o período de carência, quando do uso de agrotóxicos, tem sido observado na produção de alimentos, pois reconhecem como essencial o cumprimento deste tempo para que o alimento não contenha quantidade elevada de resíduos, tornando-se prejudicial à saúde. A comercialização dos produtos agrícolas, cujo índice de agrotóxicos está acima do permitido, caracteriza comercialização de alimentos de forma ilegal e, por isso, é necessário levar em consideração o período de carência para a comercialização e o consumo (Abrasco, 2012).

Quanto à segurança, constatou-se que os agricultores nem sempre utilizam equipamento de proteção individual. Percebe-se que há uma preocupação e cuidado com a saúde no momento da aplicação desses produtos, porém, não são todos os agricultores que usam proteção como preconiza a Embrapa (2003), ao recomendar o uso de máscaras protetoras, óculos, chapéu de abas largas, macacão com mangas compridas e avental impermeável. Um estudo semelhante realizado por Bohner, Araújo e Nishijima (2013), no município de Chapecó-SC, também indicou que nem todos os agricultores usam equipamento de proteção individual quando realizam aplicação de agrotóxicos.

Em relação aos riscos de trabalhar com agrotóxicos, todos os produtores rurais entendem que há periculosidade. A prática do uso de equipamento de proteção individual é seguida parcialmente pelos trabalhadores, relatando que a indevida utilização dos equipamentos de proteção individual se dá pelo desconforto térmico e dificuldade de locomoção. Por essas razões, é comum deparar-se com trabalhadores rurais sem o uso de equipamentos durante a aplicação e manuseio desses produtos (Morri et al., 2015).

A aplicação de agrotóxicos requer equipamentos que propiciem a segurança do trabalhador, no entanto, ainda são frequentes as aplicações com pulverizador costal, como constatado neste estudo. Essa técnica expõe de forma direta o agricultor pelo contato do equipamento com o corpo e pelo tempo durante o qual o produtor fica exposto ao agrotóxico, especialmente considerando a frequência de aplicação que pode chegar a oito vezes por mês. A aplicação realizada com tratores diminui parcialmente os riscos de intoxicação, pois os trabalhadores ficam em uma posição mais afastada dos agrotóxicos se comparada à situação de uso de pulverizadores costais (Abrasco, 2012; Londres, 2011).

Para minimizar os problemas causados pelo uso constante de agrotóxicos, é necessário treinamentos e sensibilização dos produtores, com intuito de aumentar a adesão ao uso dos equipamentos de proteção individual, uma vez que este recurso é o principal meio adotado para evitar problemas toxicológicos tanto para o homem quanto para o meio ambiente. 
Quanto às condições climáticas, todos os agricultores têm como critério pulverizar as plantações com agrotóxicos quando o clima estiver apropriado. Em caso de chuva ou muito vento, evitam a aplicação do produto. Segundo a Embrapa (2005), a aplicação deve ser efetuada em temperaturas entre $20 \circ \mathrm{C}$ e $30 \circ \mathrm{C}$, umidade relativa do ar entre $70 \%$ e $90 \%$ e ventos inferiores a 10 $\mathrm{km} / \mathrm{h}$. Entretanto, há uma "deriva técnica", ou seja, há dispersão de agrotóxicos no meio ambiente levado pelo vento ou água. Normalmente acontece com os atuais equipamentos de pulverização, pois mesmo com a calibração, temperatura e ventos ideais, os pulverizadores têm uma eficácia de $32 \%$ de retenção dos agrotóxicos nas plantas, ficando 19\% à deriva no ar, $49 \%$ chegando até o solo e outra parte alcançando o lençol freático (Abrasco, 2012; Londres, 2011).

Embora o estudo não tenha realizado análises da água e do solo para verificar a contaminação causada por esses produtos, argumenta-se que o descarte inadequado das embalagens e as técnicas impróprias de compra, manejo e aplicação de agrotóxicos, como observado em algumas práticas relatadas, podem proporcionar desequilíbrio e contaminação ambiental, animal e vegetal, provocando instabilidade no ecossistema, além de aumentar a resistência das pragas a esses insumos. Salienta-se que parte dos agricultores não realiza a devolução das embalagens vazias no local de compra, como preconiza a Lei n. 9.974, sendo responsabilidade do produtor armazená-las e inutilizá-las, a fim de evitar o seu reaproveitamento (Embrapa, 2005; Brasil, 2000).

Os principais agrotóxicos utilizados pelos produtores rurais são os inseticidas, fungicidas e herbicidas, sendo que estes também são citados pela Associação Brasileira de Saúde Coletiva (2012), como o de maior relevância para a saúde pública os quais são responsáveis por ocasionar intoxicações agudas e efeitos adversos crônicos principalmente quando os agricultores referem não receber orientação no momento da aquisição buscando-as com amigos e vizinhos. Esses produtos seguem uma classificação toxicológica quanto ao perigo que representam para quem os manuseia e entra em contato de forma direta ou indireta, sendo expressa em valores de dose média letal, por via oral $\left(D L_{50}\right)$, toxicidade dérmica $\left(D_{50}\right)$, toxicidade inalatória aguda (CL50), cutânea, ocular e potencial carcinogênico. Essas doses são representadas por miligramas do produto tóxico por quilo de peso vivo (Embrapa, 2003).

Tendo em vista seu poder toxicológico, os sintomas indicados pelos agricultores após aplicação, como dor de cabeça, fraqueza, irritação nos olhos, boca e garganta, podem caracterizar condições de intoxicação aguda. Já as intoxicações crônicas não foram citadas pelos agricultores, o que pode ser explicado pelo fato de serem agravos de mais difícil diagnóstico, uma vez que não têm sintomas bem definidos e confundem-se facilmente com outras doenças. Contudo, a ação dos agrotóxicos no organismo é insidiosa e cumulativa, podendo se manifestar de forma tardia (Kós et al., 2013; Murussi et al., 2014; Ubessi et al., 2015).

\section{CONCLUSÃO}

De maneira geral, é possível afirmar que o uso de agrotóxicos pelos agricultores familiares da região Oeste Catarinense é uma constante na produção da maioria dos alimentos cultivados nas propriedades. Embora haja certa preocupação com a proteção da saúde e com o meio ambiente quando da aplicação desses produtos, evidenciou-se fragilidades na utilização de equipamentos 
de proteção individual, destino adequado das embalagens e carência de orientações e assistência sobre o uso correto de agrotóxicos, o que poderia contribuir para o cultivo de alimentos mais saudáveis, desenvolvimento de práticas sustentáveis, manutenção da cadeia produtiva, conservação e minimização dos efeitos adversos dos agrotóxicos sobre a saúde humana e o ambiente.

Em relação às práticas de uso e manuseio de agrotóxicos na produção de alimentos na agricultura familiar e os aspectos de saúde dos agricultores, observa-se casos de intoxicações. Contudo, somente as situações de intoxicações agudas são notórias pelos agricultores, isso possivelmente ocorre pelos sintomas imediatos gerados no organismo. Já as intoxicações crônicas são pouco reconhecidas por esses trabalhadores, pois os prejuízos à saúde vêm ao longo do tempo, não se identificando o nexo-causal do agravo. Diante dessa constatação, torna-se imprescindível abordar, num processo de educação à saúde, a temática 'uso e manuseio de agrotóxicos e salubridade ocupacional-ambiental' junto aos agricultores familiares, numa perspectiva de autocuidado e empoderamento frente essa problemática.

\section{REFERÊNCIAS}

Agência Nacional de Vigilância Sanitária. (2011). Programa de Análise de Resíduos de Agrotóxicos em Alimentos (PARA). ANVISA: Autor. Recuperado de http://portal.anvisa.gov.br/wps/content/Anvisa+Portal/Anvisa/Inicio/Agrotoxicos+e+Toxicol ogia/Assuntos+de+Interesse/Programa+de+Analise+de+Residuos+de+Agrotoxicos+em+Alime ntos

Alencar, J. A. (2010). Cultivo da videira: normas gerais sobre o uso de agrotóxicos. (2a ed.). Empresa Brasileira de Pesquisa Agropecuária. Recuperado de http://sistemasdeproducao.cnptia.embrapa.br/FontesHTML/Uva/CultivodaVideira_2ed/agro toxicos.html

Augusto, L. G. S.; Carneiro, F. F.; Rigotto, R. M.; Friedrich, K.; Búrigo, A. C. (2012). Dossiê Um alerta sobre os impactos dos agrotóxicos na saúde: agrotóxicos, saúde, ambiente e sustentabilidade. Associação Brasileira de Saúde Coletiva. Rio de Janeiro: ABRASCO, 2012.

BADALOTTI, R.; RENK, A.; FILIPPIN, E. S. (2007). Reprodução social da agricultura familiar e juventude rural no oeste catarinense. In Anais da Reunião de Antropologia do Mercosul, Porto Alegre, RS, Brasil, 7: Universidade Federal do Rio Grande do Sul, 1, 97-108.

Bohner, T. O. L., Araújo, L. E. B., Nishijima, T. (2013) O impacto ambiental do uso de agrotóxicos no meio ambiente e na saúde dos trabalhadores rurais. Santa Maria Revista Eletrônica do Curso de Direito da UFSM, 8(3), 329-341. Recuperado de https://periodicos.ufsm.br/revistadireito/article/view/8280 DOI: 10.5902/19813694

Casal, V. B., Azevedo, L. F., Ferreira, R. P., Silva, D. G., Simão, R. S. (2014). Agrotóxicos: uma revisão de suas consequências para a saúde pública. Revista Eletrônica em Gestão, Educação e Tecnologia Ambiental, 18(1), 437-445. Recuperado de https://periodicos.ufsm.br/reget/article/view/12498/pdf. DOI: 10.5902/22361170 
Cizenando, T. A. L. (2012). Uso de agrotóxicos nas pequenas propriedades produtoras de banana no município de Ipanguaçu/RN. (Monografia). Universidade Federal Rural do Semiárido Campus Angicos, Angicos, Rio Grande do Norte, Brasil.

Empresa Brasileira de Pesquisa Agropecuária. (2003). Uso de agrotóxicos: Normas gerais para o uso de agrotóxicos. Recuperado de $<$ https://sistemasdeproducao.cnptia.embrapa.br/FontesHTML/Banana/BananaJuazeiro/agro toxicos.htm

Empresa Brasileira de Pesquisa Agropecuária. (2005). Normas sobre o uso de agrotóxicos. Recuperado de https://sistemasdeproducao.cnptia.embrapa.br/FontesHTML/Pimenta/PimenteiradoReino/p aginas/uso.htm

Empresa de Pesquisa Agropecuária e Extensão Rural de Santa Catarina. (2015). Síntese Anual da Agricultura de Santa Catarina 2014-2015. Florianópolis: Autor. Recuperado de http://docweb.epagri.sc.gov.br/website_cepa/publicacoes/Sintese_2015.pdf

Gomes, M. A. F., Barizon, R. R. M. (2014). Panorama da Contaminação Ambiental por Agrotóxicos e Nitrato de origem Agrícola no Brasil: Cenário 1992/2011. Jaguariúna, SP: Embrapa. Recuperado https://www.infoteca.cnptia.embrapa.br/bitstream/doc/987245/1/Doc98.pdf

Kós, M. I., Hoshino, A. C., Asmus, C. I. F., Mendonça, R., Meyer, A. (2013) Efeitos da exposição a agrotóxicos sobre o sistema auditivo periférico e central: uma revisão sistemática. Revista Saúde Pública, 29 (8), 1-16.

Lei n. 9.974, de 6 de junho de 2000. Dispõe sobre a pesquisa, a experimentação, a produção, a embalagem e rotulagem, o transporte, o armazenamento, a comercialização, a propaganda comercial, a utilização, a importação, a exportação, o destino final dos resíduos e embalagens, o registro, a classificação, o controle, a inspeção e a fiscalização de agrotóxicos, seus componentes e afins, e dá outras providências. Brasília, 2000. Recuperado de http://www010.dataprev.gov.br/sislex/paginas/42/2000/9974.htm

Londres, F. (2011). Agrotóxicos no Brasil: um guia para ação em defesa da vida. Rio de Janeiro: Assessoria e Serviços a Projetos em Agricultura Alternativa. Recuperado de https://contraosagrotoxicos.org/wp-content/uploads/2016/12/Agrotoxicos-no-BrasilINTERNET.pdf.

Minetto, M. (2013). Produção de alimentos para autoconsumo na agricultura familiar em Santo Ângelo/RS. Cadernos de Agroecologia, 8 (2), 1-5.

Mori, N. C., Horn, R. C., Oliveira, C., Leal, P. A. P., Golle, D. P., Koefender, J., Bortolotto, J.; Dias, H. M. (2015). Alterações bioquímicas e toxicológicas de agricultores familiares da região do Alto Jacuí, Rio Grande do Sul. Revista Scientia Medica, Rio Grande do Sul, 24 (3), 1-7.

Murussi, C., Hornl, R. C., Santill, A., Clasenll, B. E., Reisl, G., Souza, D., Bortolotto, J. W., Manfio, C. E., Loro, V. L. (2014) Changes in oxidative markers, endogenous antioxidants and activity of 
the enzyme acetylcholinesterase in farmers exposed to agricultural pesticides - a pilot study. Santa Maria, Revista Ciência Rural, 44 (7), 1-8.

NETTO, S. N. (2007). A responsabilidade do controle no uso de agrotóxicos: seus reflexos no atual ordenamento brasileiro. (Trabalho de Conclusão de Curso). Universidade Regional de Blumenau, Blumenau, SC, Brasil.

Ubessi, L., Ubessi, D., Ubessi, C., Kirchner, R. M., Jardim, V. M. R., Stumm, E. M. F. (2015). Uso de equipamentos de proteção por agricultores que utilizam agrotóxicos na relação com problemas de saúde. Recife. Revista de Enfermagem, 9 (4), 7230-7238.

Vargas, L., Gleber, L. (2005). Tecnologia de aplicação de defensivos. Empresa Brasileira de Pesquisa Agropecuária. https://sistemasdeproducao.cnptia.embrapa.br/FontesHTML/Ameixa/AmeixaEuropeia/tecn ologia.htm 